\title{
Advanced heart failure: state of the art and future directions
}

\author{
Daniele Masarone ${ }^{1, *}$, Michelle Kittleson ${ }^{2}$, Andrea Petraio ${ }^{3}$, Giuseppe Pacileo ${ }^{1}$ \\ ${ }^{1}$ Heart Failure Unit, Department of Cardiology, AORN dei Colli Monaldi Hospital, 80131 Naples, Italy \\ ${ }^{2}$ Department of Cardiology, Smidt Heart Institute, Cedars-Sinai, Los Angeles, CA 90048, USA \\ ${ }^{3}$ Heart Transplant Unit, Department of Cardiac Surgery and Transplants, AORN dei Colli Monaldi Hospital, 80131 Naples, Italy \\ *Correspondence: daniele.masarone@ospedalideicolli.it (Daniele Masarone) \\ Academic Editors: Giuseppe Biondi-Zoccai, Mariangela Peruzzi and Antonio Abbate \\ Submitted: 8 December 2021 Revised: 14 January 2022 Accepted: 18 January 2022 Published: 8 February 2022
}

\begin{abstract}
Advanced heart failure is a clinical challenge that requires a pathophysiological-based approach. As the field has been the subject of multiple reviews, the objective of this paper is not to duplicate these publications but rather to offer practical tips for the clinical cardiologist to enable the optimal management of patients with advanced heart failure. Advanced heart failure is defined as a clinical syndrome characterized by severe and persistent symptoms, most commonly with severe ventricular dysfunction, despite optimized medical therapy. This review covers the management of the advanced heart failure patient from pharmacologic therapy with diseasemodifying drugs, to the use of electrical therapy devices, percutaneous valve repair and finally to the role of left ventricular assist devices and heart transplantation. The review also explores future directions in the management of advanced heart failure, including translational perspectives for the treatment of this syndrome.
\end{abstract}

Keywords: advanced heart failure; acutely decompensated heart failure; inotropes; left ventricular assist device; HeartMate 3; heart transplant

\section{Introduction}

Despite improvements in pharmacological and nonpharmacological treatments for patients with heart failure (HF) with reduced ejection fraction (HFrEF) [1], up to $13 \%$ of patients do not respond to conventional approaches, resulting in disease progression to the most advanced stage of HF [2].

Advanced HF (AdvHF) is defined as a clinical syndrome characterized by severe and persistent symptoms, often with severe ventricular dysfunction, despite optimized medical therapy [3]. Acutely decompensated HF, on the other hand, is defined as the appearance of new or worsening signs and symptoms of HF, often leading to hospitalization or presentation to the emergency department. Frequent episodes of acutely decompensated HF are one of the hallmarks of AdvHF. Patients with AdvHF present a management challenge for the clinical cardiologist. For these patients, triage to options including titration of diseasemodifying drugs [4], myocardial revascularization, repair of severe mitral or tricuspid valvular insufficiency [5], implantation of a ventricular assist device [6], or heart transplant evaluation [7] requires additional knowledge, skills, and experience beyond that acquired during a fellowship in cardiovascular medicine. To help clinical cardiologists better manage this challenging clinical syndrome, this review summarizes the pathophysiology, diagnosis, and therapeutic options of AdvHF.

\section{Definition and diagnostic criteria of AdvHF}

AdvHF has a highly unpredictable clinical course, which complicates early diagnosis and timely referral to a third-level center. While in some cases, AdvHF progresses rapidly to cardiogenic shock, in other cases it evolves slowly over time (indolent progressive shock) [8,9]. Therefore, in the most recent definitions of AdvHF, data on functional capacity, quality of life, cardiac structure/function, and biomarkers have been added as essential complements to define AdvHF, even in the presence of apparent clinical stability (Table 1, Ref. [10-12]).

\section{Pathophysiology and clinical presentation of AdvHF}

Patients with AdvHF manifest a specific hemodynamic profile characterized by high left ventricular filling pressure (resulting in congestion) and low cardiac output (resulting in systemic hypoperfusion) [13]. Orthopnea and elevated jugular venous pressure are typical symptoms and signs of high left ventricular filling pressure [14]. In addition to these "traditional" signs and symptoms, bendopnea (i.e., dyspnea that occurs when a patient leans forward, such as when bending over to tie shoes) is a specific symptom of AdvHF [15]. Conversely, rales, described as pathognomonic of chronic HF, are absent in $>80 \%$ of patients with AdvHF (with chronically elevated filling pressure due to pulmonary lymphatic vessel compensation) [16]. On the other hand, peripheral edema is generally unrelated to left 
Table 1. Definition of AdvHF according to international society guidelines and consensus papers.

\begin{tabular}{|c|c|c|}
\hline AHA/ACC [10] & HFSA [11] & HFA [12] \\
\hline $\begin{array}{l}\text { Two or more episodes of acutely decompensated HF in the last } \\
12 \text { months }\end{array}$ & $\begin{array}{l}\text { Two or more episodes of acutely decompensated HF in the last } \\
12 \text { months }\end{array}$ & $\begin{array}{l}\text { Two or more episodes of acutely decompensated HF in the } \\
\text { last } 12 \text { months due to pulmonary or systemic congestion, } \\
\text { low output state or malignant ventricular arrhythmias }\end{array}$ \\
\hline Progressive reduction of renal function & Progressive deterioration in renal and hepatic function & $\begin{array}{l}\text { Severe cardiac dysfunction as defined by reduced left ven- } \\
\text { tricular ejection fraction } \leq 30 \% \text {, isolated right-ventricle fail- } \\
\text { ure, or inoperable severe valve diseases }\end{array}$ \\
\hline Cardiac cachexia & $\begin{array}{l}\text { Severe reduction of exercise capacity as documented by a peak } \\
\mathrm{VO}_{2}<14 \mathrm{~mL} / \mathrm{kg} / \mathrm{min} \text { (or }<50 \% \text { predicted) at cardiopulmonary } \\
\text { exercise test or a distance }<300 \mathrm{~m} \text { at } 6 \text {-minute walking-test }\end{array}$ & $\begin{array}{l}\text { Severe reduction of exercise capacity as documented by a } \\
\text { peak } \mathrm{VO}_{2}<14-12 \mathrm{~mL} / \mathrm{kg} / \mathrm{min} \text { at cardiopulmonary exercise } \\
\text { test or a distance }<300 \mathrm{~m} \text { at } 6 \text {-minute walking-test estimated } \\
\text { to be of cardiac origin }\end{array}$ \\
\hline Intolerance to disease-modifying drugs & Intolerance to disease-modifying drugs & NYHA class III-IV \\
\hline NYHA class III-IV & NYHA class III-IV & $\begin{array}{l}\text { Cachexia, liver or renal dysfunction due to HF or type } 2 \text { pul- } \\
\text { monary hypertension }\end{array}$ \\
\hline Hypotension (SBP $<90 \mathrm{mmHg}$ ) & Diuretic refractoriness associated with worsening renal function & \\
\hline $\begin{array}{l}\text { Need of escalated diuretic therapy or addition of metolazone in } \\
\text { the last month }\end{array}$ & $\begin{array}{l}\text { Three or more sustained episodes of ventricular tachycardia, } \\
\text { ventricular fibrillation or appropriate implantable cardioverter- } \\
\text { defibrillator shocks during a 24-hour period }\end{array}$ & \\
\hline $\begin{array}{l}\text { Three or more sustained episodes of ventricular tachycardia, } \\
\text { ventricular fibrillation or appropriate implantable cardioverter- } \\
\text { defibrillator shocks during a } 24 \text {-hour period }\end{array}$ & Persistent low serum sodium (usually $<133 \mathrm{mEq} / \mathrm{L}$ ) & \\
\hline Persistent low serum sodium (usually $<133 \mathrm{mEq} / \mathrm{L}$ ) & $\begin{array}{l}\text { Worsening right HF and type II pulmonary hypertension } \\
\text { Need for intravenous inotropic therapy for symptomatic relief } \\
\text { or to maintain organ perfusion }\end{array}$ & \\
\hline
\end{tabular}

Abbreviations: AHA/ACC, American Heart Association/American College of Cardiology; HFSA, Heart Failure Society of America; HFA, Heart Failure Association; HF, Heart Failure; VO ${ }_{2}$, Volume of Oxygen; SBP, Systolic Blood Pressure; NYHA, New York Heart Association. 


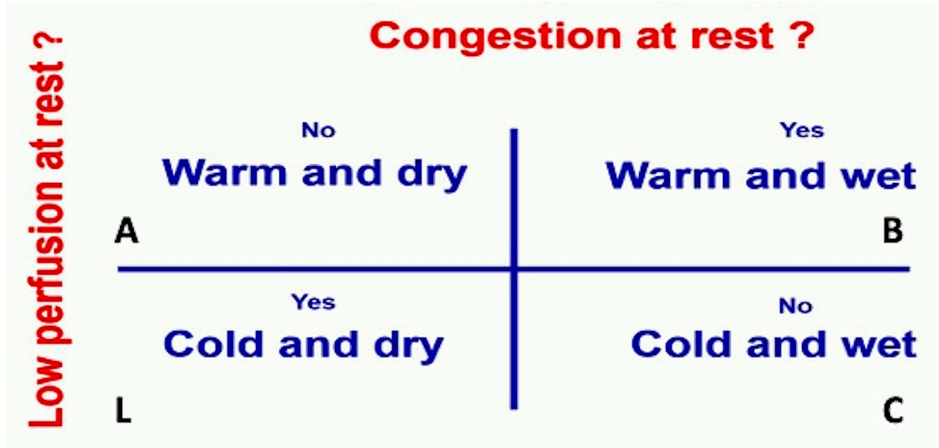

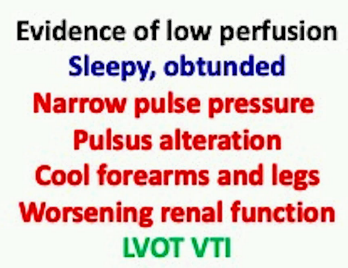

Fig. 1. Clinical (blue), "old" (red), and "new" (green) echocardiographic features of patients with AdvHF according to hemodynamic profile. Abbreviations: LVOT VTI, Left Ventricular Outflow Tract Velocity-Time Integral.

ventricular filling pressure, but rather to increased central venous volume. The most accessible evidence of perfusion is blood pressure, which requires careful auscultation to determine pulse-pressure amplitude. A proportional pulse pressure $<25 \%$ suggests a low output state (i.e., cardiac index $<2.2 \mathrm{~L} / \mathrm{min} / \mathrm{m}^{2}$ ) in patients with AdvHF [17]. This finding requires further confirmation, particularly in elderly patients with less compliant vessels. Altered mental status may be a sign of severely reduced organ perfusion; patients may report somnolence after meals or extreme generalized fatigue and weakness [18,19].

Furthermore, cold forearms and legs, or more specifically cold hands and feet, are present in the low cardiac output syndrome [20]. Finally, a typical symptom of low organ perfusion is the occurrence of symptomatic hypotension following the administration of disease-modifying drugs (even at low doses) [21]. Fig. 1 summarizes the symptoms and signs of the hemodynamic profile of HF. Notably, these hemodynamic profiles are useful not only for diagnosis; but for prognosis as well. In a series of 486 patients with AdvHF, $67 \%$ had a B profile (wet and warm), $28 \%$ had a C profile (cold and wet), and only $5 \%$ were found to be cold and dry. At 1-year follow-up, death and cardiac transplantation rates were twice as high in patients with $\mathrm{C}$ profiles than B profiles [22].

\section{Referral of patients with AdvHF to an AdvHF center}

In view of the potential increase in mortality and morbidity due to late initiation of advanced therapy for AdvHF, any red flags suggesting advanced HF should be identified at every patient encounter. Fortunately, many eas- ily recognized clinical signs and events indicate that a patient with apparent clinical stability has AdvHF. Clinical elements characterizing a particularly poor prognosis are those indicating labile hemodynamic compensation, such as recurrent hospitalizations, intolerance to guideline-directed medical therapy, increasing arrhythmic burden (atrial fibrillation and complex ventricular arrhythmias), and worsening renal and hepatic function. A mnemonic for remembering these elements is "I NEED HELP" [23] (Fig. 2). This acronym is useful for early referral to an AdvHF specialist before the onset of irreversible multiorgan dysfunction precludes candidacy for surgical therapy (i.e., mechanical circulatory support or heart transplantation) [24].

It is essential to note that a HF hospitalization is a sentinel event, and the presence of two or more hospitalizations for $\mathrm{HF}$ in the prior 12 months identifies a patient with 1-year mortality $>40 \%[25]$. The intolerance to disease-modifying drugs is also associated with a poor prognosis [26,27]. The presence of a burden of complex ventricular tachyarrhythmias (sustained ventricular tachycardias/ventricular fibrillation) with or without appropriate defibrillator shocks also indicates a worrying prognosis $[28,29]$. The presence of even a single red flag should signal further investigation which may include a cardiopulmonary exercise test and right-heart catheterization [30] as well as referral to an AdvHF center.

\section{Pharmacological therapy}

Pharmacological treatment of patients with AdvHF is based on guideline-directed medical therapy with diseasemodifying drugs, diuretics, and inotropes. 

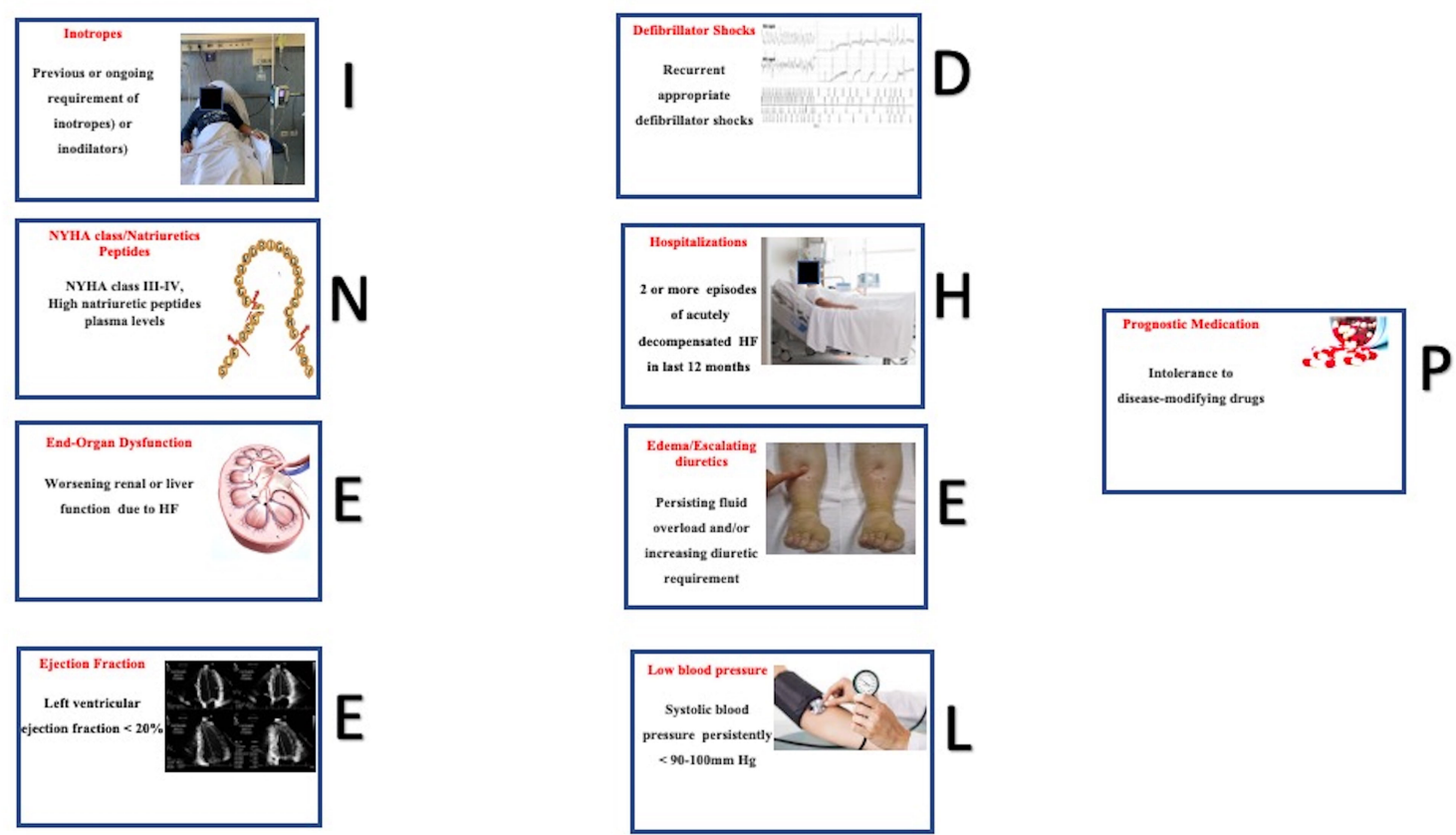

Fig. 2. I NEED HELP acronym to identify patients with AdvHF that should be referred to a tertiary center. Abbreviations: HF, Heart Failure; NYHA, New York Heart Associations.

\subsection{Disease-modifying drugs}

The use of disease-modifying drugs in patients with AdvHF represents a clinical challenge, due to factors limiting the use of these drugs (e.g., hypotension, renal dysfunction, and electrolyte alterations). This section describes the clinical trial evidence and practical strategies for optimizing disease-modifying drug use in AdvHF.

\subsection{1 $\beta$-blockers}

$\beta$-blockers antagonize the hyperactivated sympathetic nervous system in patients with HFrEF [31]. The benefit of $\beta$-blockers in patients with HFrEF was shown in several randomized clinical trials that documented reduction in mortality and hospitalizations compared to placebo.

The only trial that enrolled patients with AdvHF is the COPERNICUS trial that enrolled $2289 \mathrm{HF}$ patients with severe reduction of left ventricular ejection fraction $(<25 \%)$ and symptoms at rest or minimal exertion (NYHA class IIIIV) for at least 2 months despite optimized medical therapy that were randomized to carvedilol or placebo [32]. Patients in the carvedilol group had a significant reduction of mortality compared to patients in the placebo group (relative risk reduction 35\%, interquartile range (IQR), [19\%-48\%]).

However, there is no definite evidence on the effect of $\beta$-blockers on the quality of life of patients with AdvHF; studies had a small sample size and therefore were not conclusive. Therefore, B-blockers should always be used in conjunction with other disease-modifying drugs.

Based on these data and international society guidelines, we recommend the use of $\beta$-blockers in all patients with AdvHF, with a preference for those with more mi- nor hypotensive effects (bisoprolol and sustained-release metoprolol), starting with low doses (bisoprolol $1.25 \mathrm{mg}$ or metoprolol succinate $12.5 \mathrm{mg}$ ) and cautious and slow up-titration (50\% increase every $2-4$ weeks). In patients with AdvHF in whom $\beta$-blockers are not tolerated or for whom heart rate (in sinus rhythm) remains over 70 beats per minute on maximum-tolerated $\beta$-blockers, ivabradine should be considered [33].

\subsubsection{Renin-angiotensin-aldosterone system modulators}

Optimizing therapy with drugs that antagonize the renin-angiotensin-aldosterone system (RAAS) is a clinical challenge in patients with AdvHF due to the risk of hypotension, worsening of renal function, and electrolyte abnormalities [34].

Sacubitril-valsartan is widely used not only in patients with HFrEF but also in those with AdvHF, due to improved clinical and hemodynamic outcomes $[35,36]$.

The PARADIGM-HF trial enrolled 8442 patients with HFrEF on optimized medical therapy randomized to sacubitril/valsartan and enalapril. The study was stopped early after a median follow-up of 27 months due to the significant benefit of sacubitril/valsartan $(20 \%$ reduction in relative risk of cardiovascular mortality and $21 \%$ reduction in HF-related hospitalizations) [37].

The LIFE study involving sacubitril/valsartan was found not to be superior compared to valsartan with respect to reducing N-terminal pro-B-type natriuretic peptide (NT-proBNP) levels in patients with AdvHF and there was no difference in a composite clinical end-point (number of days alive out of hospital and without heart failure events) 
[38]. However, it was not powered to determine significance for relevant clinical endpoints. Thus, despite the negative results of that trial, we believe that sacubitril-valsartan is a valid therapeutic option in patients with AdvHF. In all patients, we recommend a starting dose of 24/26 mg twice daily or an even lower starting dose of 24/26 mg $1 / 2$ tab twice daily, then switching to $24 / 26 \mathrm{mg}$ twice daily. Slow up-titration should be performed in AdvHF patients, with a $50 \%$ increase in the daily dose every 2 weeks. Titration of sacubitril/valsartan is likely to be better tolerated than titration of $\beta$-blockers, since sacubitril/valsartan offers the acute hemodynamic benefit of afterload reduction in addition to long-term beneficial neurohormonal modulation.

Diuretic therapy may need to be reduced given the natriuretic properties of sacubitril $[39,40]$. The use of sacubitril/valsartan should be prioritized in patients with low blood pressure over other vasodilator drugs such as nitrates. In cases of intolerance to sacubitril-valsartan, treatment with an angiotensin converting enzyme (ACE) inhibitor or, if not tolerated, an angiotensin receptor blocker (ARB), should be initiated with once daily evening dosing to minimize daytime symptomatic hypotension [41]. In the CONSENSUS and SOLVD trials, even low dose ACE inhibitors resulted in a significant reduction in mortality as well as improvement in. quality of life by reducing symptoms related to hypotension $[42,43]$.

\subsubsection{Mineralocorticoid-receptor antagonists}

The most effective strategy for complete RAAS inhibition is combining Angiontensin Receptor Neprilysin Inhibitor (ARNI)/ACE inhibitors/ARBs with mineralocorticoid-receptor antagonists [44]. In the RALES trial, even in patients with AdvHF, spironolactone reduce mortality (relative risk $0.70,95 \%$ CI $0.60-0.82 ; p$ $<0.001$ ) and hospitalization (relative risk $0.65,95 \% \mathrm{CI}$ $0.54-0.77 ; p<0.01$ ) [45]. Furthermore, in this population, the advantage of this treatment was maintained even in patients with renal impairment or mild hyperkalemia [46]. For these reasons, even in the absence of definitive evidence on the effect of these drugs on the improvement of quality of life, we recommend for all patients with AdvHF and serum $\mathrm{K}^{+}<5 \mathrm{mEq} / \mathrm{L}$; the cautious introduction of low doses of spironolactone $(12.5 \mathrm{mg})$ with titration after $2-4$ weeks to the target dose of $25 \mathrm{mg}$ daily and periodic checks of potassium levels. If potassium levels are $>6 \mathrm{mEq} / \mathrm{L}$ after introducing mineralocorticoid receptor-antagonist treatment, we recommend discontinuing all drugs that interact with the RAAS. The development of new medications for the treatment of hyperkalemia (patiromer and ZS9) may optimize RAAS-modifier therapy even in patients with AdvHF [47]. However, little evidence exists to guide the use of potassium binders with hyperkalemia in response to RAAS-modifiers, and the benefit versus the increase in cost and polypharmacy needs to be weighed.

\subsubsection{Sodium-glucose cotransporter-2 (SGLT2) inhibitors}

This new class of diabetic drugs, with a pleiotropic organ-protective effect at the cardiac and renal levels, reduces HF hospitalizations and has recently been shown to decrease cardiovascular mortality in a randomized clinical trial [48]. In the DAPA-HF trial, use of dapagliflozin was associated with a reduction in the primary end point (a composite end point of cardiovascular mortality and HF hospitalizations), with a $26 \%$ relative risk reduction regardless of the presence of diabetes, and a significant reduction in cardiovascular mortality alone [49]. In the EMPERORReduced study [50], use of empagliflozin also resulted in a $25 \%$ reduction in the primary end point (cardiovascular death or HF hospitalizations) but no reduction in mortality alone [hazard ratio (HR) $0.92,95 \%$ CI $0.75-1.12$ ].

Both drugs also reduce the progression of chronic kidney disease, a frequent co-morbidity in patients with HF, regardless of the presence of diabetes; and lead to improved quality of life.

While there are no trials targeted at the AdvHF population, we recommend the addition of an SGLT2 inhibitor to RAAS-modifiers and $\beta$-blockers if tolerated; based on blood pressure and renal function in an attempt to offer patients the greatest reduction in HF morbidity and mortality.

\subsection{Diuretics}

Virtually all patients with AdvHF have some degree of chronic congestion and thus need diuretics [51]. High doses of loop diuretics are the gold standard therapy for the treatment of peripheral congestion in patients with AdvHF [52]. However, the use of these drugs may perpetuate the pathophysiological processes responsible for the progression of HF (RAAS hyperactivation, hyperactivation of the sympathetic nervous system) and contribute to diuretic resistance [53]. Both neprilysin inhibitors and SGLT2 inhibitors have diuretic properties and may work to relieve congestion without a detrimental neurohormonal impact. The addition of a thiazide diuretic or metolazone (a thiazide-like diuretics) in accordance with the sequential nephron-blockade strategy, may induce powerful diuresis [54], but increases the risk of hypokalemia (which could be avoided or corrected by adding high doses of aldosterone antagonists). In patients unresponsive to sequential nephron blockade, other treatment strategies are required, as shown in Fig. 3.

\subsection{Inotropes}

In patients with AdvHF, several inotropic and vasopressor agents with different mechanisms of action (Table 2) may be used as long-term palliative therapies or as a bridging solution to left ventricular assist device (LVAD) implantation and heart transplantation [55].

Because conventional inotropes $(\beta$-adrenergic agonists, phosphodiesterase 3 inhibitors) act through an increase in intracellular calcium concentration and hence carry an increased risk of ventricular arrhythmias, peri- 


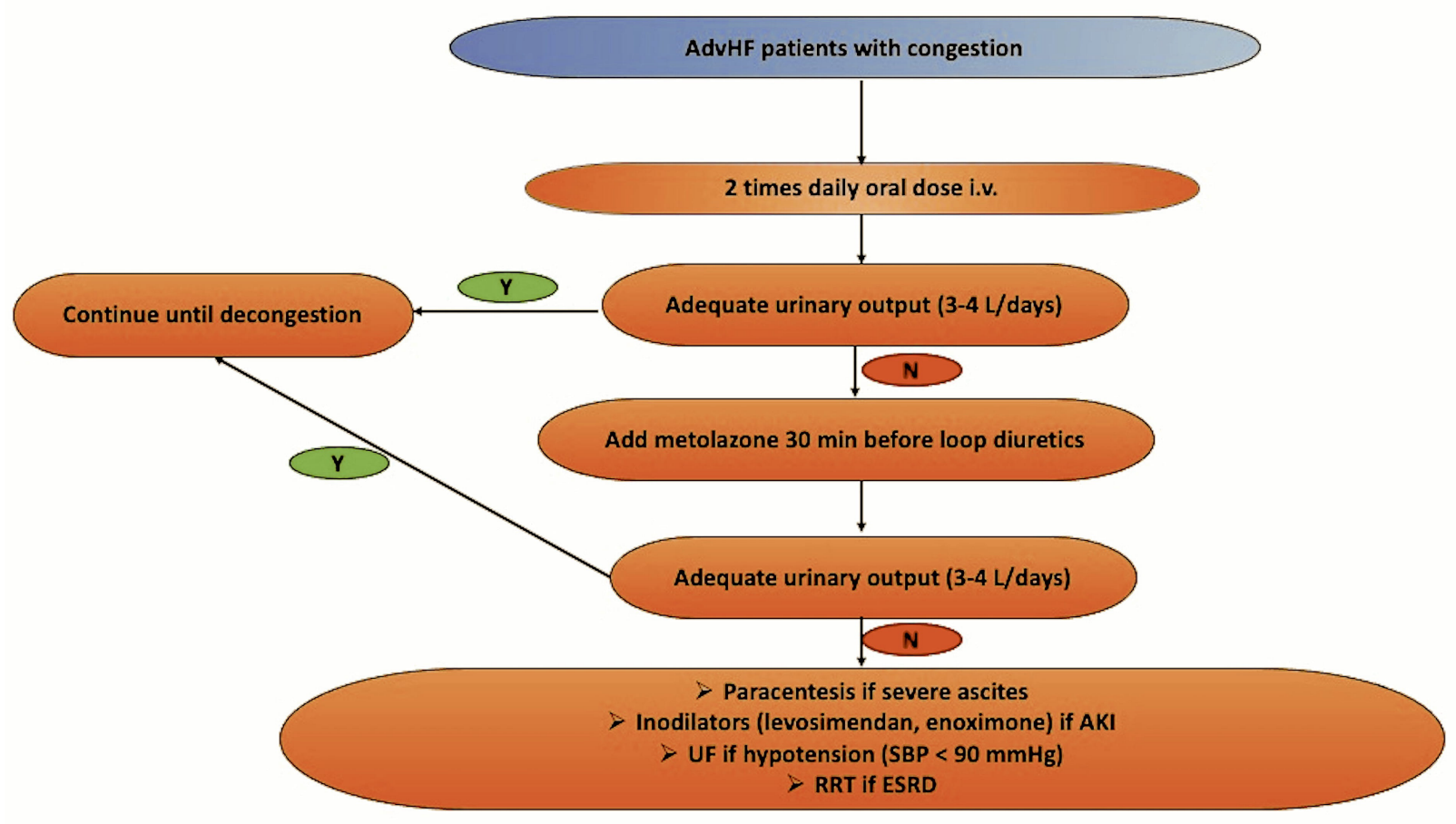

Fig. 3. Algorithm for management of congestion in patients with AdvHF. Abbreviations: UF, Ultrafiltration; AKI, Acute Kidney Injury; RRT, Renal Replacement Therapy; SBP, Systolic Blood Pressure; ESRD, End-Stage Renal Disease.

odic infusion of levosimendan may be a better option for patients with AdvHF [56]. In fact, levosimendan has a mechanism of action that does not result in an increase in intracytoplasmic calcium concentration; it is a calciumsensitizing drug that selectively increases the affinity of troponin $\mathrm{C}$ for calcium in a concentration-dependent manner. In addition, due to the activation of adenosine triphosphate (ATP)-dependent $\mathrm{K}$ channels of smooth muscle cells, levosimendan causes systemic and pulmonary vasodilation and activation of ATP-dependent $\mathrm{K}$ channels of mitochondria which is responsible for organ protection [57]. Levosimendan has a more prolonged pharmacological action (1014 days) than other inotropic drugs, due to the long halflife (about 80 hours) of its active metabolite-OR1896. In clinical trials and a single-center study, ambulatory infusion of levosimendan improved functional capacity and quality of life and reduced hospitalizations in outpatients with advanced HFrEF [58,59] without an increase in arrhythmic burden. Moreover, an echocardiographic pilot study showed that 6 hours' infusion of levosimendan increased cardiac index and cardiac output and reduced left atrial pressure and pulmonary pressure in outpatients with AdvHF [60].

For these reasons, we believe that intermittent use of levosimendan is a viable treatment option for some patients with AdvHF, particularly those with a contraindication to LVAD implantation or heart transplantation (destination therapy) or as a bridge to these treatment options. However, levosimendan is not available in the United States. In inotrope-dependent AdvHF patients in the United States, dobutamine, milrinone, and dopamine are most commonly used for palliation or as a bridge to advanced therapies [61].

\section{Cardiac electronic device-based therapy}

Cardiac implantable electronic device therapy has become an essential therapeutic option for managing both lifethreatening ventricular arrhythmias and systolic dysfunction in AdvHF patients [62]. In its broadest application, it includes both devices that prevent sudden cardiac and devices that improve cardiac performance, such as cardiac resynchronization therapy (CRT) or cardiac contractilitymodulation therapy (CCM) [63]. Since the use of devices for the prevention of sudden death occurs predominantly in the early stages of HFrEF; and given the fact that AdvHF patients' mortality is essentially related to the progression of HF, rather than sudden death, in the following sections we describe the roles of CRT and CCM in patients with AdvHF.

\section{$6.1 C R T$}

CRT is the treatment of choice for HFrEF patients with left ventricular ejection fraction (LVEF) $<35 \%$ and a wide QRS interval [64]. International guidelines recommend CRT in patients with HF, LVEF $<35 \%$, who remain symptomatic (NYHA class II-IV) despite optimal medical therapy, and have a left bundle-branch block (LBBB) with a QRS duration $>150 \mathrm{~ms}$ [65]. Several randomized clinical trials of CRT have been performed involving more than 
Table 2. Clinical pharmacology of inotropes and vasopressor use in patients with AdvHF.

\begin{tabular}{|c|c|c|c|}
\hline Pharmacologic agent & Mechanism of action & Hemodynamic effects & Dose \\
\hline \multirow{3}{*}{ Dopamine } & \multirow{3}{*}{$\mathrm{DR}>\mathrm{b} 1>\mathrm{a}$} & Increase $\mathrm{CO} / \mathrm{CI}$ & No bolus dosing \\
\hline & & Increase PVR/SVR & Infusion dose: $1-20 \mathrm{~g} / \mathrm{kg} / \mathrm{min}$ \\
\hline & & Increase HR & 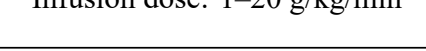 \\
\hline \multirow{3}{*}{ Dobutamine } & \multirow{3}{*}{$\mathrm{b} 1>\mathrm{b} 2>\mathrm{a}$} & Increase $\mathrm{CO} / \mathrm{CI}$ & No bolus dosing \\
\hline & & Reduce PVR/SVR & Infuriond $200 /$ - \\
\hline & & Increase HR & Infusion dose: $2-20 \mathrm{~g} / \mathrm{kg} / \mathrm{m} 1 \mathrm{n}$ \\
\hline \multirow{2}{*}{ Milrinone/Enoximone } & \multirow{2}{*}{ PD3 inhibitors } & Increase $\mathrm{CO} / \mathrm{CI}$ & Bolus dosing: $20-50 \mathrm{~g} / \mathrm{kg} / \mathrm{min}$ \\
\hline & & Reduce PVR/SVR & Infusion dose: $0.2-0.75 \mathrm{~g} / \mathrm{kg} / \mathrm{min}$ \\
\hline \multirow{2}{*}{ Levosimendan } & \multirow{2}{*}{ Calcium sensitizer } & Increase $\mathrm{CO} / \mathrm{CI}$ & No bolus dosing \\
\hline & & Reduce PVR/SVR & Infusion dose: $0.05-0.2 \mathrm{~g} / \mathrm{kg} / \mathrm{min}$ \\
\hline \multirow{2}{*}{ Norepinephrine } & \multirow{2}{*}{$\mathrm{a}>\mathrm{b} 1>\mathrm{b} 2$} & Increase $\mathrm{CO} / \mathrm{CI}$ & No bolus dosing \\
\hline & & Increase PVR/SVR & Infusion dose: $0.1-1 \mathrm{~g} / \mathrm{kg} / \mathrm{min}$ \\
\hline \multirow[b]{2}{*}{ Epinephrine } & \multirow[b]{2}{*}{$\mathrm{a}>\mathrm{b} 1>\mathrm{b} 2$} & Increase $\mathrm{CO} / \mathrm{CI}$ & No bolus dosing \\
\hline & & $\begin{array}{c}\text { Increase PVR/SVR } \\
\text { Increase HR }\end{array}$ & Infusion dose: $0.01-0.2 \mathrm{~g} / \mathrm{kg} / \mathrm{min}$ \\
\hline
\end{tabular}

Abbreviations: CI, Cardiac Index; CO, Cardiac Output; DR, Dopaminergic Receptors; HR, Heart Rate; PVR,

Pulmonary Vascular Resistance; SVR, Systemic Vascular Resistance.

Table 3. Principal characteristic of novel device for transcatheter mitral annuloplasty.

\begin{tabular}{|c|c|c|c|c|c|}
\hline Name of device & Type of device & CE appro & A appr & oval $\mathrm{N}^{\circ}$ of patients in trials & Results \\
\hline Cardioband & Direct annuloplasty & Yes & No & 92 & $\begin{array}{l}\text { Reduction of degree of mitral } \\
\text { regurgitation in } 68 \% \text { of patients with } \\
\text { significant improvement in functional } \\
\text { status and quality of life }\end{array}$ \\
\hline Mitralign & Direct annuloplasty & No & No & 71 & $\begin{array}{l}\text { Reduction of degree of mitral } \\
\text { regurgitation in } 50 \% \text { of patients with } \\
\text { significant improvement in functional } \\
\text { status and quality of life }\end{array}$ \\
\hline Carillon & Indirect annuloplasty & Yes & No & 278 & $\begin{array}{l}\text { Reduction of degree of mitral } \\
\text { regurgitation in } 50 \% \text { of patients with } \\
\text { significant improvement in functional } \\
\text { status and quality of life }\end{array}$ \\
\hline
\end{tabular}

8500 patients with HFrEF, NYHA class II-IV symptoms, and a QRS $>120 \mathrm{~ms}$ [66]. These trails clearly demonstrate that CRT reduces mortality and morbidity in HFrEF patients and improves functional capacity, exercise capacity, and quality of life. Irrespective of NYHA class, CRT results in reduced ventricular volumes, increased ejection fraction, and reduced functional mitral regurgitation (also known as reverse remodeling) [67]. These improvements occur most prominently in patients with LBBB and QRS $>150 \mathrm{~ms}$, although they can also be seen in patients with left bandle brunch block (LBBB) and QRS duration between 120-149 milliseconds [68]. In contrast, in patients with QRS $<130$, CRT results in a worse prognosis. The Echo-CRT study, enrolled 809 patients with HFrEF, NYHA class III or IV, a LVEF of $35 \%$ or less, a QRS duration of less than $130 \mathrm{msec}$, and echocardiographic evidence of left ventricular dyssyn- chrony. This trial was stopped early due to an increased mortality in the CRT group compared to control (11.1\% vs. 6.4\%; HR 1.81; 95\% CI 1.11-2.93; $p=0.02$ ) [69].

Based on these data, we recommend CRT in patients with HFrEF NYHA functional class II-IV with left ventricular ejection fraction $<35 \%$ and left bundle-branch block (or ventricular pacing dependence) on optimized medical therapy. Considering these criteria, only $20 \%-30 \%$ of patients with HFrEF are candidates for CRT, for the other 70\% of patients, a novel therapeutic available option is CCM.

\section{$6.2 C C M$}

$\mathrm{CCM}$ is an innovative therapy for treating patients with HF. It acts through the delivery of biphasic, longduration $(\sim 20 \mathrm{~ms})$, and relatively high-voltage $(\sim 7.5 \mathrm{~V})$ electrical pulses during the absolute refractory period [70]. 
Table 4. Hemodynamics effects and clinical indications of temporary mechanical circulatory support systems.

\begin{tabular}{|c|c|c|c|c|}
\hline Name of device & Type of support & nodinamic effects & Indications & Notes \\
\hline IABP & $\begin{array}{l}\text { Minimal hemodynamic support } \\
\qquad(0.3-0.5 \mathrm{~L} / \mathrm{min})\end{array}$ & $\begin{array}{c}\uparrow \mathrm{CO} \\
\downarrow \text { LVEDP } \\
\downarrow \text { PCWP }\end{array}$ & $\begin{array}{l}\text { AHF with low output state, } \\
\text { cardiogenic shock, } \\
\text { high risk PCI }\end{array}$ & Can be used without anticoagulation \\
\hline Impella & $\begin{array}{c}\text { Partial }(2 \mathrm{~L} / \mathrm{min}) \text { or complete } \\
\text { (5.5 L/min) left ventricular support } \\
\text { based upon the size of the outflow } \\
\text { cannula }\end{array}$ & $\begin{array}{c}\uparrow \uparrow \text { CO } \\
\downarrow \downarrow \text { LVEDP } \\
\downarrow \downarrow \text { PCWP }\end{array}$ & $\begin{array}{l}\text { AHF with low output state, } \\
\text { cardiogenic shock, } \\
\text { high risk PCI, } \\
\text { refractory malignant } \\
\text { arrhythmias }\end{array}$ & Active left ventricular unloading \\
\hline Tandem Heart & $\begin{array}{c}\text { Partial }(2 \mathrm{~L} / \mathrm{min}) \text { or complete } \\
\text { (5.5 L/min) left ventricular support } \\
\text { based upon the size of the outflow } \\
\text { cannula }\end{array}$ & $\begin{array}{c}\uparrow \uparrow \text { CO } \\
\\
\downarrow \downarrow \text { LVEDP } \\
\downarrow \downarrow \text { PCWP }\end{array}$ & $\begin{array}{l}\text { AHF with low output } \\
\text { state, cardiogenic shock, } \\
\text { high risk PCI, refractory } \\
\text { malignant arrhythmias }\end{array}$ & $\begin{array}{c}\text { Passive (indirect) left ventricular } \\
\text { unloading by decompressing the } \\
\text { left atrium } \\
\text { Requires septostomy }\end{array}$ \\
\hline Impella RP & $\begin{array}{c}\text { Partial (2 L/min) or complete } \\
\text { ( } 4 \mathrm{~L} / \mathrm{min} \text { ) right ventricular support } \\
\text { based upon the size of the outflow } \\
\text { cannula }\end{array}$ & $\begin{array}{c}\downarrow \text { RAP } \\
\downarrow \downarrow \text { PCWP }\end{array}$ & $\begin{array}{l}\text { RV failure after cardiac } \\
\text { surgery or LVAD } \\
\text { placement } \\
\text { RV failure associated to I } \\
\text { malignant ventricular } \\
\text { arrhythmias and severe mitral } \\
\text { regurgitation }\end{array}$ & $\begin{array}{l}\text { Increase of PCWP } \\
\text { Increase of native CO if preserved } \\
\text { left ventricular systolic function } \\
\text { al }\end{array}$ \\
\hline Protek Duo & $\begin{array}{c}\text { Partial }(2 \mathrm{~L} / \mathrm{min}) \text { or complete } \\
\text { ( } 4 \mathrm{~L} / \mathrm{min}) \text { right ventricular support } \\
\text { based upon the size of the outflow } \\
\text { cannula }\end{array}$ & $\begin{array}{c}\downarrow \text { RAP } \\
\downarrow \downarrow \text { PCWP }\end{array}$ & $\begin{array}{l}\text { RV failure after cardiac } \\
\text { surgery or LVAD } \\
\text { placement } \\
\text { RV failure associated to } \\
\text { malignant ventricular } \\
\text { arrhythmias, pulmonary } \\
\text { hypertension or acute } \\
\text { coronary syndrome }\end{array}$ & $\begin{array}{c}\text { Increase of PCWP } \\
\text { Increase of native CO if preserved } \\
\text { left ventricular systolic function }\end{array}$ \\
\hline VA-ECMO & $\begin{array}{l}\text { Complete biventricular support } \\
\qquad(3-7 \mathrm{~L} / \mathrm{min})\end{array}$ & $\begin{array}{c}\uparrow \uparrow \mathrm{CO} \\
\downarrow \text { RAP } \\
\uparrow \uparrow \text { LVEDP } \\
\uparrow \uparrow \text { PCWP }\end{array}$ & $\begin{array}{c}\text { AHF with low output state, } \\
\text { cardiogenic shock, refractory } \\
\text { malignant arrhythmias, } \\
\text { cardiac arrest }\end{array}$ & $\begin{array}{l}\text { May Require strategies for } \\
\text { left ventricular unloading (vent) }\end{array}$ \\
\hline
\end{tabular}

Abbreviations: CO, Cardiac Output; LVEDP, Left Ventricular End-Diastolic Pressure; PCWP, Pulmonary Capillary Wedge Pressure; RA, Right Atrial; MPAP, Mean Pulmonary Arterial Pressure; AHF, Acute Heart Failure; PCI, Percutaneous Coronary Intervention; RV, Right Ventricle; LVAD, Left Ventricular Assist Device.

As such, CCM does not cause a new contraction. In the short term, electrical stimulation by CCM results in improved calcium handling. In the long term, CCM effects several biochemical and molecular processes, such as reduced expression of fetal genes (overexpressed in the failing myocardium), improved calcium cycling, and ultimately myocardial contraction [71,72]. Randomized clinical trials have shown that CCM can lead to a reduction in hospitalizations and an improvement in functional capacity and quality of life in patients with HF. However, the survival benefit of CCM has not been prospectively elucidated due to short-term follow-up in existing clinical trials.
In 68 patients with previous CCM implantation retrospectively followed for 4.5 years, this therapy resulted in lower mortality rates than predicted by the Seattle Heart Failure Model (SHFM) (14.2\% at 5 years compared with the SHFM predicted rate of $27.7 \%$ ) [73].

In another retrospective single-center study that enrolled 81 patients with CCM, at a mean follow-up of three years, these patients had improvements in ejection fraction, quality of life as measured by the Minnesota Living with Heart Failure questionnaire, and a reduction in symptoms [74]. These patients had lower mortality rates than predicted by the Meta-Analysis Global Group in Chronic Heart Failure scores. 
Recent results from the largest published registry to date, CCM-REG25-45, documented survival rates of patients with LVEF $<35 \%$ to be significantly higher than survival predicted by the SHFM $(p=0.46)$ [75]. Based on this evidence, CCM may be considered in patients with AdvHF who are not candidates for heart transplant or LVAD (destination therapy) or as a bridge therapy to these treatments.

\section{Percutaneous valve repair}

Secondary (functional) mitral and tricuspid regurgitation are common in patients with AdvHF, and contribute negatively to symptoms and prognosis [76,77]. For this reason, new devices for transcatheter therapy of mitral and tricuspid regurgitation have been studied, and are now valid therapeutic options for selected patients with AdvHF.

\subsection{Percutaneous repair of mitral regurgitation}

The MitraClip System (Abbott, Abbott Park, IL, USA), which provides transcatheter edge-to-edge repair of the mitral valve, is the most widely used device for the treatment of secondary mitral regurgitation in patients with HFrEF. To date, $>90,000$ patients with severe mitral insufficiency have been treated with the MitraClip system. This represents an important non-surgical treatment option for patients with secondary mitral regurgitation who are still symptomatic despite optimized drug therapy and CRT (if indicated) and who are at high surgical risk [78]. Two landmark randomized studies have compared the MitraClip with drug therapy for secondary mitral regurgitation: COAPT and MITRA-FR $[79,80]$. In the COAPT study, patients undergoing MitraClip implantation had, at a 2-year followup, a reduction in mortality, reduced rehospitalizations, and improved quality of life compared with patients on medical therapy alone. In the MITRA-FR study, on the other hand, no change in mortality, re-hospitalizations and quality of life at 1-year follow-up was observed between the two treatment arms. The differences in outcomes between these studies were most likely due to the fact that MITRA-FR included patients with more left ventricular dilation (left ventricular end-diastolic volume index $135 \mathrm{~mL} / \mathrm{m}^{2}$ in MITRAFR vs. $101 \mathrm{~mL} / \mathrm{m}^{2}$ in COAPT) and less severe mitral regurgitation (higher prevalence of patients with effective regurgitant orifice area $<30 \mathrm{~mm}^{2}$ in MITRA-FR) than COAPT, which enrolled patients with more severe functional mitral insufficiency and less dilated ventricles [81].

The MitraBridge registry enrolled 119 patients with severe functional mitral regurgitation and AdvHF that had undergone Mitralclip implantation. At 1-year follow-up, $64 \%$ of patients remained free from adverse events [82]. Based on these data and according to the recent European Society of Cardiology guidelines on diagnosis and management of HF [83], we recommend MitraClip implantation in patients with AdvHF and severe secondary mitral regurgitation that meet the inclusion criteria of COAPT.

\subsection{Transcatheter mitral annuloplasty}

In view of the findings that all valves with significant chronic mitral regurgitation have a certain degree of annular dilatation, and that the restoration of the physiological configuration of the annulus will improve the coaptation of the leaflets [84], in recent years several devices have been tested for direct or indirect percutaneous annuloplasty. Since these devices are still in the "embryonic" phase of research, a detailed description of these novel devices is beyond the scope of this review. Table 3 provides a summary of the most commonly used devices currently available in clinical practice.

\section{Percutaneous repair of tricuspid regurgitation}

Over the last decade, an increased understanding of the pathophysiology of tricuspid regurgitation and its detrimental effects, has led to the development of new devices for the percutaneous treatment of the tricuspid valve. To date, several devices have been approved for the treatment of functional tricuspid insufficiency. The data from the TriValve registry (which collects data on different devices) showed a procedural success rate of $72.8 \%$, irrespective of the devices used [85]. A recent case-control study demonstrated that percutaneous treatment of tricuspid insufficiency at 1-year follow-up, resulted in improved survival (mortality $23.3 \%$ vs. $36.3 \%, p<0.001$ ) reduced hospitalizations for HF (26.3\% vs. $47.3 \%, p<0.0001)$ and better quality of compared with medical treatment alone [86]. Despite these promising results, the role of tricuspid valve repair in the management of patients with AdvHF is still not fully understood, and for this reason we recommend that the decision on whether to repair the tricuspid valve percutaneously must be "tailored" for each patient after careful evaluation by the heart team.

\section{Surgery}

The surgical treatment of end-stage HF has evolved significantly over the last several years [87]. Surgical options must be considered for AdvHF patients with severe symptoms and poor quality of life despite optimal medical and electrical device therapies [88]. Long-term surgical strategies for patients with AdvHF include LVAD and heart transplantation [89]. A detailed description of shortterm temporary circulatory support systems that are sometimes used as a bridge to transplantation or LVAD in patients with cardiogenic shock, is beyond the scope of this review. However, in Table 4, we briefly describe the most commonly used devices for short-term circulatory support.

\subsection{LVAD}

LVAD therapy has evolved rapidly in recent years; and the latest generation of devices have improved durability, reduced surgical and thromboembolic complications, and 
Table 5. Summarizes the principal indications and contraindications for LVAD implantation.

\begin{tabular}{ll}
\hline Indications Contraindications & C
\end{tabular}

LVEF $<25 \%$ and unable to exercise for HF, or if able to perform cardiopulmonary exercise testing, with peak $\mathrm{VO}_{2}<12 \mathrm{~mL} / \mathrm{kg} / \mathrm{min}$ and $/$ or $<50 \%$ predicted value

Three or more HF hospitalizations in previous 12 months without an obvious precipitating cause

Dependence on IV inotropic therapy or temporary MCS

Progressive end-organ dysfunction (worsening renal and/or hepatic function, type II pulmonary hypertension, cardiac cachexia) due to reduced perfusion and not to inadequately low ventricular filling pressure (PCWP $\geq 20 \mathrm{mmHg}$ and SBP $\leq 90 \mathrm{mmHg}$ or cardiac index $\leq 2 \mathrm{~L} / \mathrm{min} / \mathrm{m}^{2}$ )

Abbreviations: LVEF, Left Ventricular Ejection Fraction; HF, Heart Failure; MCS, Mechanical Circulatory Support; PCWP, Pulmonary Capillary Wedge Pressure; SBP, Systolic Blood Pressure; TR, Tricuspid Regurgitation.

Table 6. Indications and contraindications for heart transplants.

\begin{tabular}{ll}
\hline Indications & Contraindications \\
\hline $\mathrm{VO}_{2} \leq 12 \mathrm{~mL} / \mathrm{kg} /$ min in maximal cardiopulmonary exercise test & Fixed pulmonary hypertension (PVR $>5$ Wood units) \\
in patients using b-blockers & \\
$\mathrm{VO}_{2} \leq 14 \mathrm{~mL} / \mathrm{kg} / \mathrm{min}$ in maximal cardiopulmonary exercise test & Severe cerebrovascular diseases \\
in patients not using b-blockers & \\
$\mathrm{VO}_{2}<50 \%$ predicted in maximal cardiopulmonary exercise test & Severe peripheral vascular diseases \\
in young patients ( $<50$ years) and women & \\
$\mathrm{VE} / \mathrm{VCO}_{2}>35$ in submaximal test & Severe liver or renal failure \\
Chronic coronary syndrome with refractory angina and with no & Severe pulmonary disease \\
possibility of revascularization & \\
Persistent and refractory ventricular arrhythmia & Severe psychiatric disease, chemical dependence, and \\
& poor compliance with treatment \\
\hline
\end{tabular}

improved patient survival [90]. Mechanical support with an LVAD can be used to maintain end organ perfusion in patients with AdvHF until they can receive a heart transplant (bridge to transplant) or as long-term support (destination therapy) if the patients are not eligible for a transplantation [91].

In Table 5 are summarized the main indications and contraindications to LVAD implant.

HeartMate 3 (Abbott, Abbott Park, IL, USA) is the most recent LVAD with approval from the US Food and Drug Administration for a bridge to transplant or destination therapy. This device has a magnetically levitated centrifugal pump that reduces blood stasis and improves hemocompatibility [92]. The HeartMate 3 was compared to the axial-flow HeartMate 2 in the MOMENTUM 3 trial. The HeartMate 3 was shown to be noninferior to the HeartMate 2 in terms of survival and reduction in hospitalizations, with a significantly lower need for device replacement due to malfunction of the device (relative risk 0.84 ; $95 \%$ CI $0.78-$ 0.91; $p<0.001$ ) [93]. Also, stroke, major bleeding, and gastrointestinal hemorrhage were decreased in the centrifugal flow-pump group compared to the axial flow-pump group. Based on these results, HeartMate 3 is now the de- vice of choice for destination therapy and bridge therapy in patients with AdvHF, INTERMACS class 2-4, and preserved right ventricular function.

\subsection{Heart transplantation}

Heart transplantation is the gold-standard therapy for selected patients with AdvHF (Table 6). It results in significant improvements in survival, quality of life, and functional status compared with conventional treatments [94]. Improved selection of transplant candidates and improved posttransplant management of organ rejection have resulted in significant improvements in 1-year survival (>90\%) and long-term survival, which now averages 12.2 years [95].

The UNOS (United Network of Organ Sharing in the United States) recently changed its organ-allocation policy to decrease waiting-list mortality and achieve equitable organ distribution [96]. The most critical changes in the new allocation system include higher priority for patients with temporary mechanical circulatory support over those inpatients awaiting transplantation on inotropic support alone, and prioritization for outpatients with restrictive or hypertrophic cardiomyopathy or congenital heart disease over those with dilated cardiomyopathy. Despite 
heart transplants being the gold standard for AdvHF, organ scarcity limits the annual number of transplantations performed globally; therefore, a long-term circulatory support system will continue to be an important therapeutic alternative to heart transplantation.

\section{Translational research and future direction}

Current research focusing on myocardial recovery is desperately needed, since biochemical pathways capable of reversing, if not preventing, AdvHF would fundamentally change our approach to care.

Heart regeneration also has great potential to offer innovative therapy to treat patients with AdvHF [97]. Currently, there are several strategies for heart regeneration. Somatic stem cell transplantation has been shown in experimental models to be safe and to improve (albeit modestly) left ventricular function after myocardial infarction; primarily through paracrine mechanisms [98]. Alternatively, transplantation of induced pluripotent stem cells into the hearts of patients with AdvHF could lead (through production of new myocardiocytes) to improved myocardial performance [99].

More recently, direct cardiac reprogramming has emerged as a novel technology to regenerate damaged myocardium by directly converting endogenous cardiac fibroblasts into induced cardiomyocyte-like cells to restore cardiac function [100].

Other unmet needs of patients with AdvHF that will need to be addressed by upcoming research include better prediction of right ventricular dysfunction post LVAD implantation, improvement in ex situ perfusion techniques in order to increase the donor pool, as well as personalized approaches to immunosuppression to maximize graft durability and minimize infectious risk [101].

\section{Conclusions}

AdvHF is a clinical syndrome which is challenging to manage. Heart transplantation represents the optimal therapeutic strategy for these patients, but organ scarcity makes LVAD implantation another necessary option. In the coming years, significant efforts must be made to develop adequate clinical scoring systems to identify patients with AdvHF who need advanced surgical therapy. However, the need for resource optimization makes the role of the AdvHF team critical in appropriate patient selection for both heart transplantation and long-term LVAD therapy. Further clinical trials are needed to clarify the role of drug therapy, percutaneous valvular interventions, and cardiac implantable electronic device therapy in patients with AdvHF.

\section{Author contributions}

DM and AP writing the original draft, MK and GP reviewer and editing the original draft.

\section{Ethics approval and consent to participate}

Not applicable.

\section{Acknowledgment}

The authors would like to thank all the medical and nursing staff of the Heart Failure Unit, AORN dei Colli and of the Smidt Heart Institute, Cedars-Sinai Medical Center, who contribute to the care of patients with advanced heart failure every day.

\section{Funding}

This research received no external funding.

\section{Conflict of interest}

The authors declare no conflict of interest.

\section{References}

[1] Metra M, Teerlink JR. Heart failure. The Lancet. 2017; 390: 1981-1995.

[2] Dunlay SM, Roger VL, Killian JM, Weston SA, Schulte PJ, Subramaniam AV, et al. Advanced Heart Failure Epidemiology and Outcomes. JACC: Heart Failure. 2021; 9: 722-732.

[3] Bozkurt B, Coats AJS, Tsutsui H, et al. Universal definition and classification of heart failure: a report of the Heart Failure Society of America, Heart Failure Association of the European Society of Cardiology, Japanese Heart Failure Society and Writing Committee of the Universal Definition of Heart Failure: Endorsed by the Canadian Heart Failure Society, Heart Failure Association of India, Cardiac Society of Australia and New Zealand, and Chinese Heart Failure Association. Eur J Heart Fail. 2021;23:352-380.

[4] Iacoviello M, Vitale E, Corbo MD, Correale M, Brunetti ND. Disease-modifier Drugs in Patients with Advanced Heart Failure. Heart Failure Clinics. 2021; 17: 561-573.

[5] Scotti A, Margonato A, Godino C. Percutaneous mitral valve repair in patients with secondary mitral regurgitation and advanced heart failure. Mini-invasive Surgery. 2020; 4: 49.

[6] Frigerio M. Left ventricular assist device: indication, timing, and management. Heart Failure Clinics. 2021; 17: 619-634.

[7] Segreti A, Verolino G, Crispino SP, Agostoni P. Listing Criteria for Heart Transplant: role of cardiopulmonary exercise test and of prognostic scores. Heart Failure Clinics. 2021; 17: 635-646.

[8] Crespo-Leiro MG, Barge-Caballero E. Advanced heart failure: definition, epidemiology, and clinical course. Heart Failure Clinics. 2021; 17: 533-545.

[9] Truby LK, Rogers JG. Advanced heart failure: epidemiology, diagnosis, and therapeutic approaches. JACC: Heart Failure. 2020; 8: 523-536.

[10] Yancy CW, Jessup M, Bozkurt B, Butler J, Casey DE, Drazner $\mathrm{MH}$, et al. $2013 \mathrm{ACCF} / \mathrm{AHA}$ guideline for the management of heart failure: a report of the American College of Cardiology Foundation/American Heart Association Task Force on Practice Guidelines. Journal of the American College of Cardiology. 2013; 62: e147-e239.

[11] Fang JC, Ewald GA, Allen LA, Butler J, Westlake Canary CA, Colvin-Adams M, et al. Advanced (stage D) heart failure: a statement from the Heart Failure Society of America Guidelines Committee. Journal of Cardiac Failure. 2015; 21: 519-534.

[12] Crespo-Leiro MG, Metra M, Lund LH, Milicic D, Costanzo MR, Filippatos G, et al. Advanced heart failure: a position statement of the Heart Failure Association of the European Society of Car- 
diology. European Journal of Heart Failure. 2018; 20: 15051535.

[13] Baig MK, Mahon N, McKenna WJ, Caforio AL, Bonow RO, Francis GS, et al. The pathophysiology of advanced heart failure. Heart \& Lung. 1999; 28: 87-101.

[14] Vader JM, Drazner MH. Clinical Assessment of Heart Failure: Utility of Symptoms, Signs, and Daily Weights. Heart Failure Clinics. 2009; 5: 149-160.

[15] Thibodeau JT, Turer AT, Gualano SK, Ayers CR, Velez-Martinez $\mathrm{M}$, Mishkin JD, et al. Characterization of a novel symptom of advanced heart failure: bendopnea. JACC: Heart Failure. 2014; 2: 24-31.

[16] King M, Kingery J, Casey B. Diagnosis and evaluation of heart failure. American Family Physician. 2012; 85: 1161-1168.

[17] Petrie CJ, Ponikowski P, Metra M, Mitrovic V, Ruda M, Fernandez A, et al. Proportional pulse pressure relates to cardiac index in stabilized acute heart failure patients. Clinical and Experimental Hypertension. 2018; 40: 637-643.

[18] Frea S, Pidello S, Canavosio FG, Bovolo V, Botta M, Bergerone $\mathrm{S}$, et al. Clinical Assessment of Hypoperfusion in Acute Heart Failure: evergreen or antique? Circulation Journal. 2015; 79: 398-405.

[19] Metra M, Ponikowski P, Dickstein K, McMurray JJV, Gavazzi A, Bergh C, et al. Advanced chronic heart failure: a position statement from the Study Group on Advanced Heart Failure of the Heart Failure Association of the European Society of Cardiology. European Journal of Heart Failure. 2007; 9: 684-694.

[20] Johnson MJ. Management of end stage cardiac failure. Postgraduate Medical Journal. 2007; 83: 395-401.

[21] Habal MV, Garan AR. Long-term management of end-stage heart failure. Best Practice \& Research. Clinical Anaesthesiology. 2017; 31: 153-166.

[22] Shah MR, Hasselblad V, Stinnett SS, Gheorghiade M, Swedberg $\mathrm{K}$, Califf RM, et al. Hemodynamic profiles of advanced heart failure: association with clinical characteristics and long-term outcomes. Journal of Cardiac Failure. 2001; 7: 105-113.

[23] Baumwol J. "I need Help"- a mnemonic to aid timely referral in advanced heart failure. The Journal of Heart and Lung Transplantation. 2017; 36: 593-594.

[24] Morris AA, Khazanie P, Drazner MH, Albert NM, Breathett K, Cooper LB, et al. Guidance for Timely and Appropriate Referral of Patients with Advanced Heart Failure: a Scientific Statement from the American Heart Association. Circulation. 2021; 144: 238-250.

[25] Setoguchi S, Stevenson LW, Schneeweiss S. Repeated hospitalizations predict mortality in the community population with heart failure. American Heart Journal. 2007; 154: 260-266.

[26] Bhagat AA, Greene SJ, Vaduganathan M, Fonarow GC, Butler J. Initiation, Continuation, Switching, and Withdrawal of Heart Failure Medical Therapies during Hospitalization. JACC: Heart Failure. 2019; 7: 1-12.

[27] Tran RH, Aldemerdash A, Chang P, Sueta CA, Kaufman B, Asafu-Adjei J, et al. Guideline-Directed Medical Therapy and Survival Following Hospitalization in Patients with Heart Failure. Pharmacotherapy. 2018; 38: 406-416.

[28] Poole JE, Johnson GW, Hellkamp AS, Anderson J, Callans DJ, Raitt MH, et al. Prognostic importance of defibrillator shocks in patients with heart failure. The New England Journal of Medicine. 2008; 359: 1009-1017.

[29] Tung R, Vaseghi M, Frankel DS, Vergara P, Di Biase L, Nagashima $\mathrm{K}$, et al. Freedom from recurrent ventricular tachycardia after catheter ablation is associated with improved survival in patients with structural heart disease: an International VT Ablation Center Collaborative Group study. Heart Rhythm. 2015; 12: 1997-2007.

[30] Kittleson MM, Prestinenzi P, Potena L. Right Heart Catheteriza- tion in Patients with Advanced Heart Failure: When to perform? Heart Failure Clinics. 2021; 17: 647-660.

[31] Masarone D, Martucci ML, Errigo V, Pacileo G. The use of $\beta$ blockers in heart failure with reduced ejection fraction. The Journal of Cardiovascular Development and Disease. 2021; 8: 101110.

[32] Packer M, Fowler MB, Roecker EB, Coats AJS, Katus HA, Krum H, et al. Effect of Carvedilol on the Morbidity of Patients with Severe Chronic Heart Failure: results of the carvedilol prospective randomized cumulative survival (COPERNICUS) study. Circulation. 2002; 106: 2194-2199.

[33] Elzeneini M, Aranda JM, Al-Ani M, Ahmed MM, Parker AM, Vilaro JR. Hemodynamic effects of ivabradine use in combination with intravenous inotropic therapy in advanced heart failure. Heart Failure Reviews. 2021; 26: 355-361.

[34] Chow MS. Assessing the treatment of congestive heart failure: diuretics, vasodilators, and angiotensin-converting enzyme inhibitors. Pharmacotherapy. 1993; 13: 82S-87S.

[35] Sauer AJ, Cole R, Jensen BC, Pal J, Sharma N, Yehya A, et al. Practical guidance on using sacubitril/valsartan for heart failure. Heart Failure Reviews. 2019; 24: 167-176.

[36] Zern EK, Cheng S, Wolfson AM, Hamilton MA, Zile MR, Solomon SD, et al. Angiotensin Receptor-Neprilysin Inhibitor Therapy Reverses Pulmonary Hypertension in End-Stage Heart Failure Patients Awaiting Transplantation. Circulation: Heart Failure. 2020; 13: e006696.

[37] Mann DL, Givertz MM, Vader JM, Starling RC, Shah P, McNulty SE, et al. Effect of treatment with sacubitril/valsartan in patients with advanced heart failure and reduced ejection fraction: a randomized clinical trial. JAMA Cardiology. 2021; 7: e214567.

[38] Vardeny O, Claggett B, Kachadourian J, Desai AS, Packer $\mathrm{M}$, Rouleau $\mathrm{J}$, et al. Reduced loop diuretic use in patients taking sacubitril/valsartan compared with enalapril: the PARADIGM-HF trial. European Journal of Heart Failure. 2019; 21: 337-341.

[39] Masarone D, Melillo E, Errigo V, Valente F, Pacileo G. Clinical relevance of transient worsening renal function after initiation of sacubitril/valsartan. Current Medical Research and Opinion. 2021; 37: 9-12.

[40] Pontremoli R, Borghi C, Perrone Filardi P. Renal protection in chronic heart failure: focus on sacubitril/valsartan. European Heart Journal - Cardiovascular Pharmacotherapy. 2021; 7: 445452.

[41] Young JB, Dunlap ME, Pfeffer MA, Probstfield JL, Cohen-Solal A, Dietz R, et al. Mortality and morbidity reduction with Candesartan in patients with chronic heart failure and left ventricular systolic dysfunction: results of the CHARM low-left ventricular ejection fraction trials. Circulation. 2004; 110: 2618-2626.

[42] Swedberg K, Kjekshus J. Effects of enalapril on mortality in severe congestive heart failure: results of the Cooperative North Scandinavian Enalapril Survival Study (CONSENSUS). The American Journal of Cardiology. 1988; 62: 60A-66A.

[43] Yusuf S, Pitt B, Davis CE, Hood WB, Cohn JN. Effect of enalapril on survival in patients with reduced left ventricular ejection fractions and congestive heart failure. The New England Journal of Medicine. 1991; 325: 293-302.

[44] Agarwal R, Kolkhof P, Bakris G, Bauersachs J, Haller H, Wada $\mathrm{T}$, et al. Steroidal and non-steroidal mineralocorticoid receptor antagonists in cardiorenal medicine. European Heart Journal. 2021; 42: 152-161.

[45] Pitt B, Zannad F, Remme WJ, Cody R, Castaigne A, Perez A, et al. The Effect of Spironolactone on Morbidity and Mortality in Patients with Severe Heart Failure. The New England Journal of Medicine. 1999; 341: 709-717.

[46] Vardeny O, Wu DH, Desai A, Rossignol P, Zannad F, Pitt B, et 
$a l$. Influence of baseline and worsening renal function on efficacy of spironolactone in patients with severe heart failure: insights from RALES (Randomized Aldactone Evaluation Study). Journal of the American College of Cardiology. 2012; 60: 20822089.

[47] Rosano GMC, Tamargo J, Kjeldsen KP, Lainscak M, Agewall S, Anker SD, et al. Expert consensus document on the management of hyperkalaemia in patients with cardiovascular disease treated with renin angiotensin aldosterone system inhibitors: coordinated by the Working Group on Cardiovascular Pharmacotherapy of the European Society of Cardiology. European Heart Journal. Cardiovascular Pharmacotherapy. 2018; 4: 180-188.

[48] Masarone D, Pacileo R, Pacileo G. Use of disease-modifying drugs in diabetic patients with heart failure with reduced ejection fraction. Heart Failure Reviews. 2021. (in press)

[49] McMurray J, Solomon SD, Inzucchi SE, Køber L, Kosiborod MN, Martinez FA, et al. Dapagliflozin in patients with heart failure and reduced ejection fraction. The New England Journal of Medicine. 2019; 381: 1995-2008.

[50] Packer M, Anker SD, Butler J, Filippatos G, Pocock SJ, Carson $\mathrm{P}$, et al. Cardiovascular and renal outcomes with empagliflozin in heart failure. The New England Journal of Medicine. 2020; 383: 1413-1424.

[51] Lombardi CM, Cimino G, Pellicori P, Bonelli A, Inciardi RM, Pagnesi M, et al. Congestion in Patients with Advanced Heart Failure: assessment and treatment. Heart Failure Clinics. 2021; 17: $575-586$.

[52] Wile D. Diuretics: a review. Annals of Clinical Biochemistry. 2012; 49: 419-431.

[53] Roush GC, Kaur R, Ernst ME. Diuretics: a review and update. Journal of Cardiovascular Pharmacology and Therapeutics. 2014; 19: 5-13.

[54] Mullens W, Damman K, Harjola V, Mebazaa A, Brunner-La Rocca $\mathrm{H}$, Martens $\mathrm{P}$, et al. The use of diuretics in heart failure with congestion - a position statement from the Heart Failure Association of the European Society of Cardiology. European Journal of Heart Failure. 2019; 21: 137-155.

[55] Masarone D, Melillo E, Gravino R, Errigo V, Martucci ML, Caiazzo A, et al. Inotropes in Patients with Advanced Heart Failure: not only palliative care. Heart Failure Clinics. 2021; 17: 587-598.

[56] Farmakis D, Agostoni P, Baholli L, Bautin A, Comin-Colet J, Crespo-Leiro MG, et al. A pragmatic approach to the use of inotropes for the management of acute and advanced heart failure: an expert panel consensus. International Journal of Cardiology. 2019; 297: 83-90.

[57] Papp Z, Agostoni P, Alvarez J, Bettex D, Bouchez S, Brito D, et al. Levosimendan Efficacy and Safety: 20 Years of SIMDAX in Clinical Use. Journal of Cardiovascular Pharmacology. 2020; 76: 4-22.

[58] Comín-Colet J, Manito N, Segovia-Cubero J, Delgado J, García Pinilla JM, Almenar L, et al. Efficacy and safety of intermittent intravenous outpatient administration of levosimendan in patients with advanced heart failure: the LION-HEART multicentre randomised trial. European Journal of Heart Failure. 2018; 20: $1128-1136$

[59] Masarone D, Valente F, Verrengia M, Ammendola E, Gravino R, D'Alterio G, et al. Efficacy and safety of repeated infusion of levosimendan in outpatients with advanced heart failure: a realworld experience. Journal of Cardiovascular Medicine. 2020; 21: 919-921.

[60] Masarone D, Melillo E, Errigo V, Martucci ML, Pacileo R, Pollesello P, et al. Haemodynamic effects of levosimendan in outpatients with advanced heart failure: an echocardiographic pilot study. Journal of Cardiovascular Pharmacology. 2022; 79: e36-e 40.
[61] Gottlieb SS, Psotka MA, Desai N, Lindenfeld J, Russo P, Allen LA. Use of Outpatient Intravenous Calcitropes for Heart Failure in the United States. Journal of Cardiac Failure. 2021; 27: 12761279.

[62] Hussein AA, Wilkoff BL. Cardiac Implantable Electronic Device Therapy in Heart Failure. Circulation Research. 2019; 124: 1584-1597.

[63] Palmiero G, Florio MT, Rubino M, Nesti M, Marchel M, Russo V. Cardiac Resynchronization Therapy in Patients with Heart Failure: what is new? Heart Failure Clinics. 2021; 17: 289-301.

[64] Moskovitch J, Voskoboinik A. Cardiac resynchronization therapy: a comprehensive review. Minerva Medica. 2019; 110: $121-138$.

[65] Abraham WT. Cardiac Resynchronization Therapy and Cardiac Contractility Modulation in Patients with Advanced Heart Failure: how to select the right candidate? Heart Failure Clinics. 2021; 17: 599-606.

[66] Glikson M, Nielsen JC, Kronborg MB, Michowitz Y, Auricchio A, Barbash IM, et al. 2021 ESC Guidelines on cardiac pacing and cardiac resynchronization therapy. European Heart Journal. 2021; 42: 3427-3520.

[67] Masarone D, Limongelli G, Ammendola E, Del Giorno G, Colimodio F, D'Andrea A, et al. Cardiac resynchronization therapy in cardiomyopathies. Journal of Cardiovascular Medicine. 2014; 15: 92-99.

[68] Keene D, Whinnett ZI. Advances in cardiac resynchronisation therapy: review of indications and delivery options. Heart. 2021. (in press)

[69] Ruschitzka F, Abraham WT, Singh JP, Bax JJ, Borer JS, Brugada $\mathrm{J}$, et al. Cardiac-resynchronization therapy in heart failure with a narrow QRS complex. The New England Journal of Medicine. 2013; 369: 1395-1405.

[70] Lyon AR, Samara MA, Feldman DS. Cardiac contractility modulation therapy in advanced systolic heart failure. Nature Reviews. Cardiology. 2013; 10: 584-598.

[71] Brunckhorst CB, Shemer I, Mika Y, Ben-Haim SA, Burkhoff D. Cardiac contractility modulation by non-excitatory currents: studies in isolated cardiac muscle. European Journal of Heart Failure. 2006; 8: 7-15.

[72] Mohri S, Shimizu J, Mika Y, Shemer I, Wang J, Ben-Haim S, et al. Electric currents applied during refractory period enhance contractility and systolic calcium in the ferret heart. American Journal of Physiology. Heart and Circulatory Physiology. 2003; 284: H1119-H1123.

[73] Kloppe A, Lawo T, Mijic D, Schiedat F, Muegge A, Lemke B. Long-term survival with Cardiac Contractility Modulation in patients with NYHA II or III symptoms and normal QRS duration. International Journal of Cardiology. 2016; 209: 291-295.

[74] Kuschyk J, Roeger S, Schneider R, Streitner F, Stach K, Rudic B, et al. Efficacy and survival in patients with cardiac contractility modulation: long-term single center experience in 81 patients. International Journal of Cardiology. 2015; 183: 76-81.

[75] Kuschyk J, Falk P, Demming T. Long-term clinical experience with cardiac contractility modulation therapy delivered by the Optimizer Smart system. European Journal of Heart Failure. 2021; 23: 1160-1169.

[76] Goel SS, Bajaj N, Aggarwal B, Gupta S, Poddar KL, Ige M, et al. Prevalence and outcomes of unoperated patients with severe symptomatic mitral regurgitation and heart failure: comprehensive analysis to determine the potential role of MitraClip for this unmet need. Journal of the American College of Cardiology. 2014; 63: 185-186.

[77] Goliasch G, Bartko PE, Pavo N, Neuhold S, Wurm R, Mascherbauer J, et al. Refining the prognostic impact of functional mitral regurgitation in chronic heart failure. European Heart Journal. 2018; 39: 39-46. 
[78] Cammalleri V, Mega S, Ussia GP, Grigioni F. Mitral and Tricuspid Valves Percutaneous Repair in Patients with Advanced Heart Failure: panacea, or Pandora's box? Heart Failure Clinics. 2021; 17: 607-618.

[79] Obadia J, Messika-Zeitoun D, Leurent G, Iung B, Bonnet G, Piriou N, et al. Percutaneous Repair or Medical Treatment for Secondary Mitral Regurgitation. The New England Journal of Medicine. 2018; 379: 2297-2306.

[80] Stone GW, Lindenfeld J, Abraham WT, Kar S, Lim DS, Mishell $\mathrm{JM}$, et al. Transcatheter Mitral-Valve Repair in Patients with Heart Failure. New England Journal of Medicine. 2018; 379: $2307-2318$

[81] Saia F. Transcatheter edge-to-edge mitral valve repair: should we stay tied to COAPT tiers? Catheterization and Cardiovascular Interventions. 2021; 98: 1413-1414.

[82] Godino C, Munafò A, Scotti A, Estévez-Loureiro R, Portolés Hernández A, Arzamendi D, et al. MitraClip in secondary mitral regurgitation as a bridge to heart transplantation: 1-year outcomes from the International MitraBridge Registry. The Journal of Heart and Lung Transplantation. 2020; 39: 1353-1362.

[83] Gasior T, Gavazzoni M, Taramasso M, Zuber M, Maisano F. Direct Percutaneous Mitral Annuloplasty in Patients with Functional Mitral Regurgitation: when and how. Frontiers in Cardiovascular Medicine. 2019; 6: 152.

[84] McDonagh TA, Metra M, Adamo M, Gardner RS, Baumbach A, Böhm M, et al. 2021 ESC guidelines for the diagnosis and treatment of acute and chronic heart failure. European Heart Journal. 2021; 42: 3599-3726.

[85] Taramasso M, Alessandrini H, Latib A, Asami M, AttingerToller A, Biasco L, et al. Outcomes after Current Transcatheter Tricuspid Valve Intervention: mid-term results from the international TriValve registry. JACC: Cardiovascular Interventions. 2019; 12: 155-165.

[86] Taramasso M, Benfari G, van der Bijl P, Alessandrini H, Attinger-Toller A, Biasco L, et al. Transcatheter versus medical treatment of symptomatic severe tricuspid regurgitation. Journal of the American College of Cardiology. 2019; 74: 2998-3008.

[87] Daneshmand MA, Milano CA. Surgical Treatments for Advanced Heart Failure. Surgical Clinics of North America. 2009; 89: 967-999.

[88] Allen LA, Stevenson LW, Grady KL, Goldstein NE, Matlock $\mathrm{DD}$, Arnold RM, et al. Decision making in advanced heart failure: a scientific statement from the American Heart Association. Circulation. 2012; 125: 1928-1952.

[89] Miller L, Birks E, Guglin M, Lamba H, Frazier OH. Use of Ven- tricular Assist Devices and Heart Transplantation for Advanced Heart Failure. Circulation Research. 2019; 124: 1658-1678.

[90] Mancini D, Colombo PC. Left Ventricular Assist Devices: a Rapidly Evolving Alternative to Transplant. Journal of the American College of Cardiology. 2015; 65: 2542-2555.

[91] Aleksova N, Chih S. The Role of Durable Left Ventricular Assist Devices in Advanced Heart Failure: Would My Patient Benefit? Can J Cardiol. 2017; 33:540-543.

[92] Sidhu K, Lam PH, Mehra MR. Evolving trends in mechanical circulatory support: Clinical development of a fully magnetically levitated durable ventricular assist device. Trends in Cardiovascular Medicine. 2020; 30: 223-229.

[93] Mehra MR, Uriel N, Naka Y, Cleveland JC, Yuzefpolskaya M, Salerno CT, et al. A Fully Magnetically Levitated Left Ventricular Assist Device: Final Report. The New England Journal of Medicine. 2019; 380: 1618-1627.

[94] Correale M, Monaco I, Tricarico L, Bottigliero D, Sicuranza M, Del Forno B, et al. Advanced heart failure: non-pharmacological approach. Heart Failure Reviews. 2019; 24: 779-791.

[95] Khush KK, Hsich E, Potena L, Cherikh WS, Chambers DC, Harhay MO, et al. The International Thoracic Organ Transplant Registry of the International Society for Heart and Lung Transplantation: Thirty-eighth adult heart transplantation report 2021; Focus on recipient characteristics. The Journal of Heart and Lung Transplantation. 2021; 40: 1035-1049.

[96] Liu J, Yang BQ, Itoh A, Masood MF, Hartupee JC, Schilling JD. Impact of New UNOS Allocation Criteria on Heart Transplant Practices and Outcomes. Transplantation Direct. 2020; 7: e642.

[97] Isomi M, Sadahiro T, Ieda M. Progress and Challenge of Cardiac Regeneration to Treat Heart Failure. Journal of Cardiology. 2019; 73: 97-101.

[98] Vaka R, Davis DR. State-of-play for cellular therapies in cardiac repair and regeneration. STEM CELLS. 2021; 39: 1579-1588.

[99] Guan X, Xu W, Zhang H, Wang Q, Yu J, Zhang R, et al. Transplantation of human induced pluripotent stem cell-derived cardiomyocytes improves myocardial function and reverses ventricular remodeling in infarcted rat hearts. Stem Cell Research \& Therapy. 2020; 11: 73.

[100] Xie Y, Liu J, Qian L. Direct cardiac reprogramming comes of age: Recent advance and remaining challenges. Seminars in Cell \& Developmental Biology. 2022; 122: 37-43.

[101] Guidetti F, Arrigo M, Frank M, et al. Treatment of Advanced Heart Failure-Focus on Transplantation and Durable Mechanical Circulatory Support: What Does the Future Hold? Heart Failure Clinics. 2021; 17: 697-708. 